\title{
Conocimientos y saber en Medicina
}

De Portugal Álvarez J. Conocimientos y saber en Medicina. An Med Interna (Madrid) 2004; 21: 1-2.

Utilizando el lenguaje de entendimiento habitual y al margen de la precisión filosófica, es posible establecer la diferencia entre conocimientos y saber e incluso buscar la articulación de ambos en el ejercicio de la mente humana. Las distintas maneras de información proveen a la mente de datos, nociones y conceptos que son almacenados en el cerebro, probablemente en las interconexiones neuronales que constituyen la memoria. Se trata, en esencia, del traslado del contenido de la información a la memoria de quien la recibe en un proceso gnoseológico de interiorización de lo externo. Los conocimientos adquiridos, seleccionados previamente por la afectividad, son almacenados tal como se reciben, colocándose, más o menos ordenadamente, en las estanterías de la memoria sin que sea obligada una activa participación intelectiva del receptor. Sin embargo, algunos de los conocimientos almacenados adquieren categorías distintas según condiciones personales, intelectuales y culturales de quien los posee y según la disposición para ser utilizados. Los conocimientos adquiridos constituyen la materia prima para el desarrollo del saber que, en esencia, consiste en el procesamiento intelectual de tales conocimientos. La elaboración y transformación de los conocimientos en ideas es la base del saber humano, un proceso dinámico que necesita imprescindiblemente de la inteligencia, previamente estimulada por un activo deseo de saber y apoyada operativamente por los saberes anteriormente establecidos.

La función principal de los conocimientos es especular, es decir, permite reconocer en el exterior el contenido de esos conocimientos. Con nuestros conocimientos somos capaces de identificar fenómenos iguales o semejantes a los que los generaron, por lo tanto, su utilización primordial es el reconocimiento. El saber utiliza obviamente el substrato de los conocimientos pero no se queda en el simple reconocimiento, sino que incorporándolos a un tejido de saberes previos, los analiza, los integra y los interpreta y es capaz de adaptarlos a situaciones nuevas. En consecuencia es posible admitir dos tipos de conducta mental en la actividad práctica. Uno simplemente adaptativo que utiliza los conocimientos y que consiste, primero en el reconocimiento del problema y después en aplicar adecuadamente sus contenidos para conseguir la solución. El otro es un proceso dinámico que utiliza el saber, que reconoce el problema mediante los conocimientos básicos, pero a partir de éstos genera una condición mental nueva de elevada categoría intelectual con lo cual se conoce completa y profundamente el problema y se dispone de más recursos mentales para solucionarlo. Es lógico deducir que la utilización de uno u otro tipo de conducta, además de tener distinta categoría intelectual, es posible que derive en diferentes consecuencias prácticas. Y sin llegar a la utilización práctica, la íntima disposición de conocimientos o de saber permite distinguir dos tipos de persona: uno, cuyo bagaje mental se reduce a los conocimientos y otro que además dispone de saber. En la vida común al primero se le reconoce como erudito y al segundo como sabio o mas sencillamente como hombre culto.

Esta artificiosa distinción epistemológica entre conocimientos y saber ha sido diseñada como instrumento que nos sirva para analizar algunos comportamientos y actitudes del médico en la práctica clínica. Es evidente que los medios de información actuales han expandido hasta el infinito la oferta de conocimientos médicos, al punto, que el clínico estudioso necesita utilizar un laborioso y riguroso proceso de selección para quedarse con lo necesario para su utilización clínica. Los conocimientos médicos que se ofertan continuamente se almacenan en soportes bibliográficos y/o informáticos, pero el médico práctico conserva en su memoria aquellos necesarios para aplicar en la clínica. En la masa, más o menos amplia, de conocimientos de cualquier médico existe un conjunto de ellos, sancionados por la experiencia o la evidencia, que son los que utiliza en su práctica clínica habitual mediante el simple acoplamiento de tales conocimientos al problema que se plantea. Las manifestaciones clínicas del problema son reconocidas e identificadas en la plantilla mental de conocimientos que el médico posee y las posibles soluciones impresas en ella son utilizadas en el diagnóstico y la terapéutica. Este tipo de conducta clínica tiene, indudablemente, defectos y riesgos, uno de estos la peligrosa tendencia a la rutina, pero es el que más se utiliza en la práctica, entre otras razones, por la inmediatez de su aplicación que hoy se adapta bien a una medicina traspasada por la prisa. Los gestores de la sanidad pública, acosados por el no leve problema de adaptar los recursos a la eficiencia y al principio ético de justicia, demandan al médico 
un tiempo establecido para la atención al paciente, que en el ámbito hospitalario se traduce en la llamada "estancia media". El cumplimiento ideal de este parámetro obliga con frecuencia al médico a una actuación acelerada cuya meta es el alta del paciente, buscado, a veces con más interés de gestión que puramente médico. Desgraciadamente hay servicios de medicina que han adquirido tal obsesión por el alta del paciente que domina prioritariamente toda su atención, cuando, como es lógico, es un acto secundario o consecuente. Este tipo de actitud, que puede sortear todas las vicisitudes de la clínica, conlleva, sin embargo, la posibilidad de problemas médicos, éticos e incluso judiciales. Pero se comprende que en las actuales condiciones de premura clínica, la conducta médica mas adecuada sea la aplicación inmediata, casi automática, sin demasiada elaboración, de los conocimientos médicos respecto al problema clínico del paciente. Incluso esos conocimientos pueden ser compensados o sustituidos por vías y protocolos clínicos convencionalmente establecidos.

Otra cosa es la actuación clínica mediante el saber medico, que es, según se ha dicho, la consecuencia del procesamiento de los conocimientos médicos. La maquinaria intelectual de este procesamiento tiene tres piezas fundamentales: la imprescindible inteligencia del médico; un primordial deseo de saber como es la realidad científica de la enfermedad y el acervo de saber médico previamente establecido. El contenido de este saber desarrollado anteriormente está constituido por un amplio tejido de principios fisiopatológicos que infunde y dirige el pensamiento del médico. El pensamiento fisiopatológico es la base del saber médico y funciona como engranaje de las piezas de conocimientos almacenadas, cohesionándolas y activándolas oportunamente para, en consecuencia, permitir un razonamiento y una práctica de elevadas cualidades médicas. Solo el pensamiento fisiopatológico hace al clínico "sabio" y le coloca en una posición óptima para afrontar los problemas patológicos. La interpretación fisiopatológica de los fenómenos clínicos facilita el más completo conocimiento de la enfermedad y conduce obligatoriamente a su consideración holística, permitiendo ocasionalmente la observación y análisis de eventuales manifestaciones atípicas de la enfermedad que pueden pasar inadvertidas con la exclusiva aplicación de conocimientos. Incluso, hipotéticamente, si existieran fenómenos clínicos hasta ahora desconocidos, el análisis fisiopatológico sería capaz de interpretarlos y con ellos descri- bir nuevos síndromes o enfermedades, porque solo el verdadero saber médico hace posible el descubrimiento.

Es deseable que el médico práctico, además de mantener el hábito de explorar oral y físicamente al paciente de la manera más completa posible, conserve su formación fisiopatológica y la aplique en la interpretación y manejo del enfermo. Esto es lo que solemos recomendar a nuestros estudiantes y residentes, bien es cierto que con afán más ilusorio que eficaz, porque la práctica actual, sobrecargada y acuciante, es poco propicia para la exploración completa y la serena meditación fisiopatológica. Incluso estas acciones pueden ser preteridas, al menos como uso habitual y absoluto, porque lo que hoy se exige al médico es un producto compuesto de buena eficacia clínica y de buenos resultados de gestión y el equilibrio deseado entre ambos componentes sólo se consigue limando bordes a la actuación clínica hasta dejarla en una operación concisa y rápida, lo más ajustada posible a la sintomatología del paciente. Se comprende que este modo de actuación sea más fácil con la aplicación oportuna de conocimientos médicos e incluso es posible admitir que con él se consigan aceptables resultados clínicos adaptables a buenos resultados de gestión. Paradójicamente la aplicación adecuada del saber médico, que obliga a una consideración completa del paciente, tiene el riesgo de desequilibrar el binomio clínica-gestión durante el periodo de estancia hospitalaria. Las cosas son así en la medicina de hoy y así hay que asumirlas porque lo demanda la sociedad, asunción no difícil, incluso imperceptible, para los clínicos nuevos, pero que en alguna medida conmueve el sentido médico de los clínicos viejos.

Sin embargo, hay que insistir, no deben perderse la formación y el pensamiento fisiopatológicos, porque el saber, el deseo de saber, es uno de los fundamentos de nuestra profesión. El otro es la voluntad de ayudar, también, por cierto, comprometido en la medicina actual. Si perdemos ambos, perdemos una profesión científica y humanamente hermosa para quedarnos con un oficio rutinario.

\section{J. DE PORTUGAL ÁLVAREZ}

Hospital Universitario Gregorio Marañón. Universidad Complutense. Madrid 